\title{
Repeat stereotactic radiosurgery for progressive vestibular schwannomas after previous radiosurgery: a systematic review and meta-analysis
}

\author{
Anne Balossier ${ }^{1,2} \cdot$ Jean Régis ${ }^{1,2} \cdot$ Nicolas Reyns $^{3,4} \cdot$ Pierre-Hugues Roche $^{5} \cdot$ Roy Thomas Daniel $^{6,7} \cdot$ Mercy George $^{8}$. \\ Mohamed Faouzi $^{9} \cdot$ Marc Levivier $^{6,7} \cdot$ Constantin Tuleasca ${ }^{6,7,10}$
}

Received: 19 January 2021 / Revised: 13 March 2021 / Accepted: 16 March 2021 / Published online: 13 April 2021

(c) The Author(s) 2021

\begin{abstract}
Vestibular schwannomas (VS) are slow-growing intracranial extraaxial benign tumors, developing from the vestibular part of the eight cranial nerves. Stereotactic radiosurgery (SRS) has now a long-term scientific track record as first intention treatment for small- to medium-sized VS. Though its success rate is very high, SRS for VS might fail to control tumor growth in some cases. However, the literature on repeat SRS after previously failed SRS remains scarce and reported in a low number of series with a limited number of cases. Here, we aimed at performing a systematic review and meta-analysis of the literature on repeat SRS for VS. Using PRISMA guidelines, we reviewed manuscripts published between January 1990 and October 2020 and referenced in PubMed. Tumor control and cranial nerve outcomes were evaluated with separate meta-analyses. Eight studies comprising 194 patients were included. The overall rate of patients treated in repeat SRS series as per overall series with first SRS was 2.2\% (range 1.2-3.2\%, $p<0.001$ ). The mean time between first and second SRS was 50.7 months (median 51, range 44-64). The median marginal dose prescribed at first SRS was 12 Gy (range 8-24) and at second SRS was $12 \mathrm{~Gy}$ (range 9.8-19). After repeat SRS, tumor stability was reported in $61 / 194$ patients, i.e., a rate of $29.6 \%$ (range $20.2-39 \%, \mathrm{I}^{2}=49.1 \%, p<0.001$ ). Tumor decrease was reported in $83 / 194$ patients, i.e., a rate of $54.4 \%$ (range $33.7-75.1 \%$, $\mathrm{I}^{2}=89.1 \%, p<0.001$ ). Tumor progression was reported in 50/188 patients, i.e., a rate of $16.1 \%$ (range $2.5-29.7 \%, \mathrm{I}^{2}=87.1 \%$, $p=0.02$ ), rarely managed surgically. New trigeminal numbness was reported in $27 / 170$ patients, i.e., a rate of $9.9 \%$ (range $1.4-18.3 \%, p<0.02$ ). New facial nerve palsy of worsened of previous was reported in $8 / 183$ patients, i.e., a rate of $4.3 \%$ (range $1.4-7.2 \%, p=0.004$ ). Hearing loss was reported in $12 / 22$ patients, i.e., a rate of $54.3 \%$ (range $24.8-83.8 \%, \mathrm{I}^{2}=70.7 \%$, $p<0.001)$. Repeat SRS after previously failed SRS for VS is associated with high tumor control rates. Cranial nerve outcomes remain favorable, particularly for facial nerve. The rate of hearing loss appears similar to the one related to first SRS.
\end{abstract}

Keywords Stereotactic radiosurgery $\cdot$ Vestibular schwannoma $\cdot$ Gamma Knife $\cdot$ Facial nerve $\cdot$ Cochlear nerve $\cdot$ Hearing

\section{Introduction}

Vestibular schwannomas (VS) are intracranial extraaxial benign tumors, slow growing, developing from the vestibular part of the eight cranial nerves [47]. They account for

Dr Balossier and Régis equally contributed as first author

Dr Levivier and Tuleasca equally contributed as senior authors

Constantin Tuleasca

constantin.tuleasca@chuv.ch;

constantin.tuleasca@gmail.com

Extended author information available on the last page of the article approximately $10 \%$ of primary brain tumors [57]. The relative incidence is $0.6-0.8$ per 100,000 individuals per year [47]. Due to the increased use of advanced radiographic imaging, and in particular contrast-enhanced magnetic resonance imaging (MRI), more and more VS are diagnosed incidentally in patients without any symptom. The most common symptom is unilateral hearing decline, followed by tinnitus and vertigo [19]. Classically, VS are frequently diagnosed around the fifth decade of life. Most of the authors report female preponderance [39]. It has been recently acknowledged that three different growth patterns are commonly described, including no/very slow growth, slow growth $(2 \mathrm{~mm} /$ year $)$, or fast growth $(>8 \mathrm{~mm} /$ year $)$ [21]. Such variety of tumor growth rates and interventional 
outcomes, including for incidentally discovered lesions, make long-term management a matter of debate [46].

The current gold standard for diagnosis is thin-cut axial MRI of the head with contrast enhancement (gadolinium) [4]. Recent evidence suggested that non-enhanced thin-slice T2-weighted MRI might be sufficient for initial screening [5]. The advantages of such approach include not only reduced risk of adverse reactions, but also reduced cost [4]. Moreover, this offers also a high contrast between the VS, cerebrospinal fluid, and the adjacent structures [36]. The T2 CISS is also considered highly sensitive and specific in detecting small VS, close to the T1 gadolinium weighted. The MRI allows evaluating volumetric course during time. Various measurements have been applied, including $\mathrm{mm} /$ year-based model, $\mathrm{cm}^{3} /$ year-based model, and a volumedoubling time (VDT)-based model. Some authors suggested that VDT-based model was the most accurate in describing VS growth [56].

Newly diagnosed VS can benefit from "wait and scan" strategy [21], stereotactic radiosurgery (SRS) [28, 43, 52], radiotherapy [51], or microsurgical resection [6, 48, 55]. Recurrent or progressive residual VS might be treated by SRS [15] or microsurgical resection [38] depending on tumor volume and patients' specific characteristics (age, medical comorbidities) [49]. In the opinion of some authors, microsurgery remains the most prevalent strategy, which is particularly applicable to large VS. However, during the recent years, there has been an increasing trend towards "wait-and-scan" [22] and SRS, the former especially for small- to medium-sized tumors, or in the frame of combined approaches, following planned subtotal resection $[6,16]$.

Stereotactic radiosurgery is beginning to have a longterm scientific track record as first intention treatment for small- to medium-sized VS, with high tumor control rates and low morbidity rates. In case of failure, which can occasionally occur, microsurgical resection is generally advocated. Recently, there is a growing literature with regard to the role of repeat SRS for growing VS after the first failed SRS treatment $[11,15]$. Thus, some authors advocated for the use of a second SRS instead of microsurgical resection, whenever possible, alone or in combination with the former, in the frame of combined approaches [55]. However, the total number of patients reported is quite low, and the exact safety and efficacy are not widely accepted. Moreover, the exact indications might vary among centers. Thus, the literature on this topic is scarce.

Here, we performed systematic review and meta-analysis of series reporting retreatment by SRS for growing VS after previously failed SRS. We have chosen this topic as, up-to-date, the literature is scarce and includes a limited number of series. Moreover, the number of patients included in the reported series is low. There are several pending questions related to the role of retreatment by SRS (after first SRS) of VS including the timing of second SRS, the tumor control, and the potential induced neuropathies (including hearing preservation) as well as how to manage radiation-induced changes, related both to tumor swelling with further pseudoprogression appearance. Thus, we describe tumor control rates, as well as cranial nerve outcomes (whenever reported), with complications and their relative incidence. We present the indications for such retreatment, as depicted in the current literature.

\section{Methods}

\section{Article selection and data extraction}

A PubMed search was performed for entries between January 1990 and October 2020 using the following query guidelines: ((vestibular AND (radiosurgery OR Gamma Knife)) AND (schwannoma) OR (retreatment)). Inclusion criteria were as follows: peer-reviewed clinical study or case series of VS retreated with SRS, independently of the device, clearly specified and presented as independent series of second SRS. Excluded were as follows: abstract, case reports, non-English studies, conference papers and series where fractionated radiotherapy was used.

Eight studies comprising 194 patients were included [7, $9,11,15,18,26,27,61]$. The detailed study characteristics can be seen in Tables 1, 2, and 3. There were only Gamma Knife (GK, Elekta Instruments, AB, Sweden) studies including reports of second SRS after a first failed SRS. No Linear Accelerator (Linac) or Cyberknife studies specifically reported outcomes following retreatment, in the frame of a separate clinical article.

The article selection is collated in Fig. 1. Two separate reviewers $(\mathrm{AB}, \mathrm{CT})$ applied the inclusion criteria to the PubMed search result; there were no disagreements.

This study was performed in accordance with the published Preferred Reporting Items for Systematic Reviews and Meta-Analyses (PRISMA) guidelines [33].

Data extraction was performed as per individual study, while paying special attention to tumor control aspects (stability, decrease, increase) and cranial nerve outcomes (pertaining to trigeminal, facial, and/or cochlear and vestibular nerves).

\section{Indication for retreatment}

Treatment failure has been heterogeneously defined among studies, usually as continuous growth requiring subsequent intervention after a minimum 2 years of follow-up [61]. Some authors classified the response to GK as regression (more than $10 \%$ volume reduction), stabilization (volume variation within 10\%), enlargement (more than $10 \%$ volume increase not requiring further intervention), and failure (uncontrollable tumor growth requiring further intervention and/or appearance of disabling radiation side effect) [61]. 


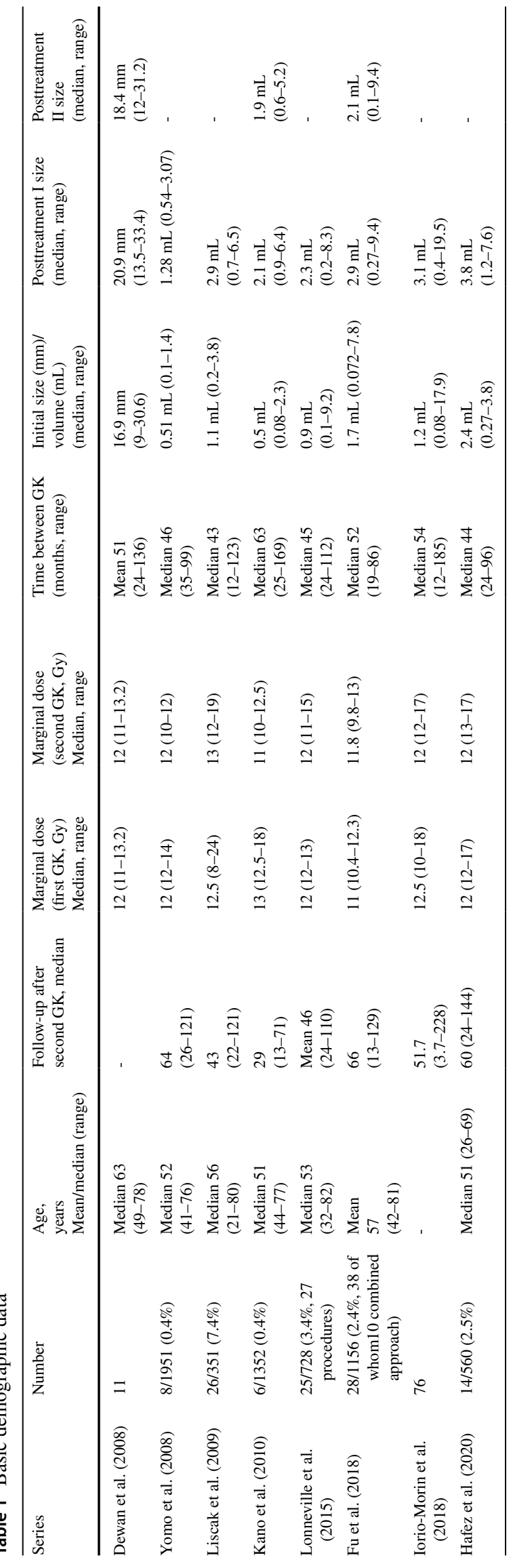

\section{Specific outcome measurements}

The House-Brackmann scale was used to asses facial nerve function [14]. The Gardner-Robertson scale was used to assess hearing function, defined as functional hearing for classes I and II [10].

\section{Adverse radiation events}

Magnetic resonance imaging (MRI) was used to assess presence of edema at cerebellar and/or brainstem level. The most frequently used sequences were T2 w (CISS) and FLAIR.

\section{Statistical analysis using OpenMeta (Analyst) and random-effects model}

Due to the high variation in study characteristics, a statistical analysis using a binary random-effects model (DerSimonianLaird method) was performed. We used OpenMeta (analyst) software from the Agency for Healthcare Research and Quality.

Weighted summary rates were determined using metaanalytical models. Testing for heterogeneity was performed for each meta-analysis.

Pooled estimates using meta-analytical techniques were obtained for all the outcomes previously described in the same section.

\section{Results}

\section{Number of patients in repeat SRS series as per overall series with first SRS}

The overall rate of patients treated in repeat SRS series as per overall series with first SRS was $2.2 \%$ (range 1.2-3.2\%, $\mathrm{I}^{2}=92.5 \%, p$ heterogeneity $\left.<0.001, p<0.001\right)$ (Fig. 2).

\section{Time between first and second SRS}

The mean time between first and second SRS was 50.7 months (median 51, range 44-64). The minimal and maximal time frames were 12 and 185 months, respectively.

\section{Marginal dose prescription}

The median marginal dose prescribed at first and second SRS were 12 Gy (range 8-24) and 12 Gy (range 9.8-19), respectively.

\section{Tumor control after repeat SRS}

Tumor stability after retreatment was reported in 61/194 patients, i.e., a rate of $29.6 \%$ (range $20.2-39 \%, \mathrm{I}^{2}=49.1 \%$, $p$ heterogeneity $0.05, p<0.001$; Fig. $3 a$ ). 


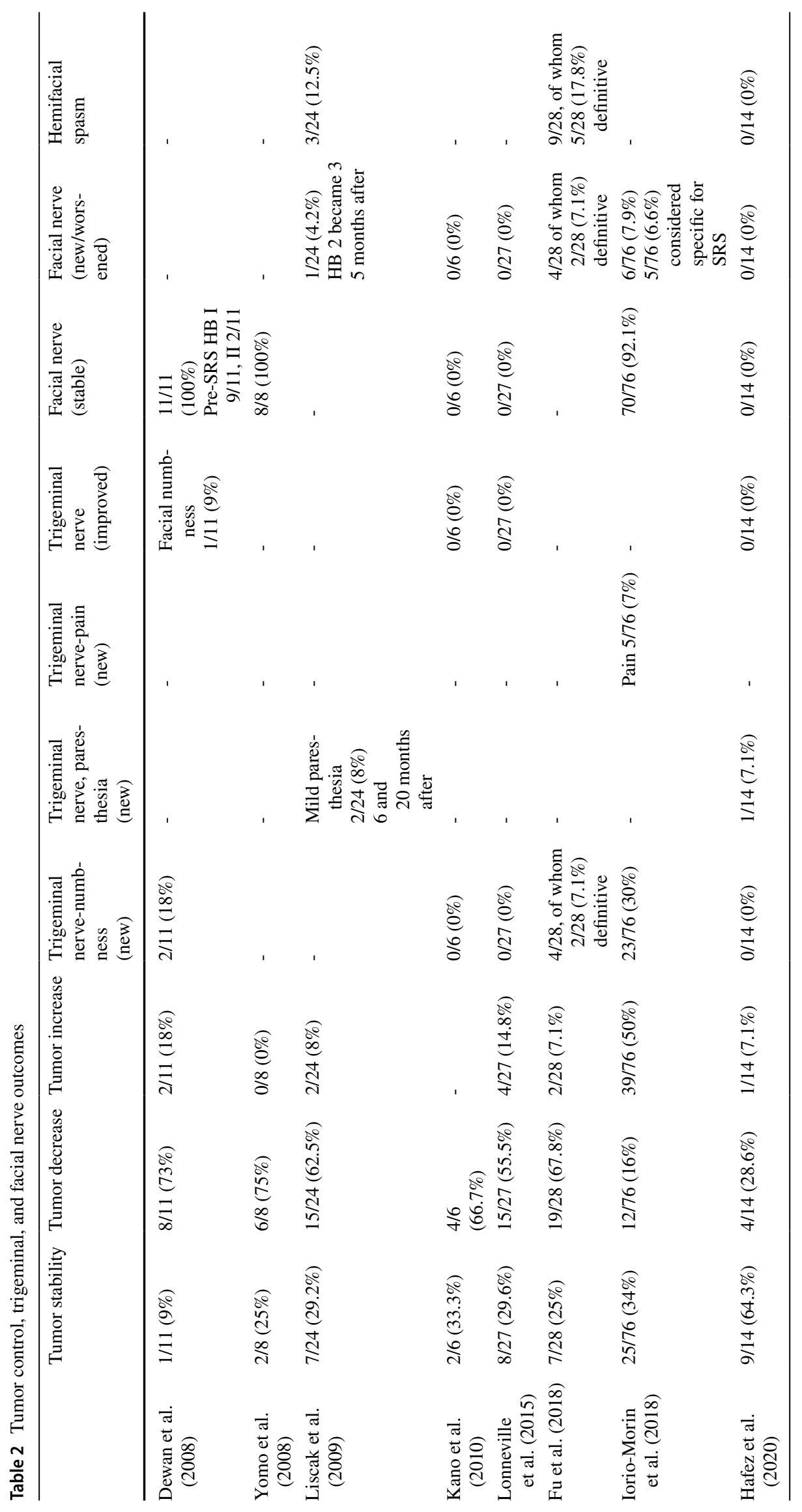


Table 3 Vestibular and cochlear nerve outcomes, TTE, ARE, and other complications, further treatment (when reported)

\begin{tabular}{|c|c|c|c|c|c|c|}
\hline & Vestibular & $\begin{array}{l}\text { Cochlear } \\
\text { (worsened) }\end{array}$ & $\begin{array}{l}\text { Transient tumor } \\
\text { expansion }\end{array}$ & $\begin{array}{l}\text { Adverse radiation } \\
\text { events (ARE) }\end{array}$ & $\begin{array}{l}\text { Other } \\
\text { complications }\end{array}$ & Further surgery \\
\hline Dewan et al. (2008) & - & $\begin{array}{l}1 / 1(100 \%) \\
\text { (10 no prior useful } \\
\text { hearing) } \\
\text { Gardner I to II }\end{array}$ & - & $\begin{array}{l}\text { 2/11 (slight transient } \\
\text { peduncular edema) }\end{array}$ & - & - \\
\hline Yomo et al. (2008) & - & $\begin{array}{l}2 / 3(66.6 \%) \\
(5 \text { no prior useful } \\
\text { hearing) }\end{array}$ & & - & - & - \\
\hline Liscak et al. (2009) & $1 / 24(4.2 \%)$ & $0 / 2(0 \%)$ & - & - & $\begin{array}{l}1 \text { ventriculo- } \\
\text { peritoneal } \\
\text { shunt } \\
\text { (22 months } \\
\text { later) }\end{array}$ & $1 / 24$ \\
\hline Kano et al. (2010) & - & $0(0 \%)$ & - & $\begin{array}{l}\text { 1/6 (slight transient } \\
\text { peduncular edema) } \\
16 \text { months after GK }\end{array}$ & - & - \\
\hline $\begin{array}{l}\text { Lonneville et al. } \\
\text { (2015) }\end{array}$ & - & $5 / 5(100 \%)$ & $12 / 28(42.8 \%)$ & - & - & - \\
\hline Fu et al. (2018) & - & $1 / 2(50 \%)$ & $12 / 28$ & $\begin{array}{l}\text { 1/28 (3.6\%) transient } \\
\text { peduncular edema } \\
\text { being hospitalized } \\
\text { (dexamethasone } \\
\text { and manitol) }\end{array}$ & - & - \\
\hline $\begin{array}{l}\text { Iorio-Morin et al. } \\
\quad(2018)\end{array}$ & $\begin{array}{c}41 / 76(55 \%) \\
\text { imbalance }\end{array}$ & $1 / 6(16.7 \%)$ & $\begin{array}{l}13 / 76(17.5 \%) \\
\text { after median of } \\
12.5 \text { months } \\
(3-24)\end{array}$ & - & - & $\begin{array}{l}8 / 76(10.5 \%) \\
3 \text { for tumor control, } \\
5 \text { for symptom } \\
\text { control (facial } \\
\text { pain, imbalance, } \\
\text { vertigo) }\end{array}$ \\
\hline Hafez et al. (2020) & - & $2 / 3(66.6 \%)$ & - & $0 / 14(0 \%)$ & - & - \\
\hline
\end{tabular}

Tumor decrease after retreatment was reported in $83 / 194$ patients, i.e., a rate of $54.4 \%$ (range $33.7-75.1 \%$, $\mathrm{I}^{2}=89.1 \%, p$ heterogeneity $p<0.001, p<0.001$; Fig. $\left.3 \mathrm{~b}\right)$.

Tumor progression after retreatment was reported in $50 / 188$ patients, i.e., a rate of $16.1 \%$ (range $2.5-29.7 \%$, $\mathrm{I}^{2}=87.1 \%, p$ heterogeneity $p<0.001, p=0.02$; Fig. 3c).

\section{Transient tumor expansion after SRS}

Transient tumor expansion after SRS was specifically reported in two series [15, 27], ranging between 17.5 and $42.8 \%$.

\section{Cranial nerve outcomes after repeat SRS}

New trigeminal numbness after retreatment was reported in $27 / 170$ patients, i.e., a rate of $9.9 \%$ (range $1.4-18.3 \%$, $\mathrm{I}^{2}=76.36 \%, p$ heterogeneity $p<0.001, p=0.02$; Fig. $4 \mathrm{a}$ ).

New facial nerve palsy of worsened facial nerve outcome of previously existing one was reported in 8/183 patients, i.e., a rate of $4.3 \%$ (range $1.4-7.2 \%, \mathrm{I}^{2}=0 \%, p$ heterogeneity $p=0.905, p=0.004$; Fig. 4b).
Hearing loss after retreatment was reported in $12 / 22$ patients, i.e., a rate of $54.3 \%$ (range $24.8-83.8 \%, \mathrm{I}^{2}=70.7 \%$, $p$ heterogeneity $p=0.002, p<0.001$; Fig. $4 c)$.

\section{Ventriculo-peritoneal shunt}

One series [26] reported the necessity of a ventriculoperitoneal shunt 22 months after second SRS in one case.

\section{Discussion}

The results of our systematic review and meta-analysis show that repeat SRS for VS remains safe and effective, as the results after a first SRS [17]. Here, we included 8 studies comprising 194 patients, all treated with GK as second SRS after a previously failed SRS for VS. We report overall tumor stability in $29.6 \%$ of cases, decrease in $54.4 \%$, and further tumor progression in $16.1 \%$. However, only a small number of cases with further progression underwent surgical resection in the reported series. This is most probably related to pseudoprogression phenomenon, although this was not 
Fig. 1 Prisma flowchart with study selection details

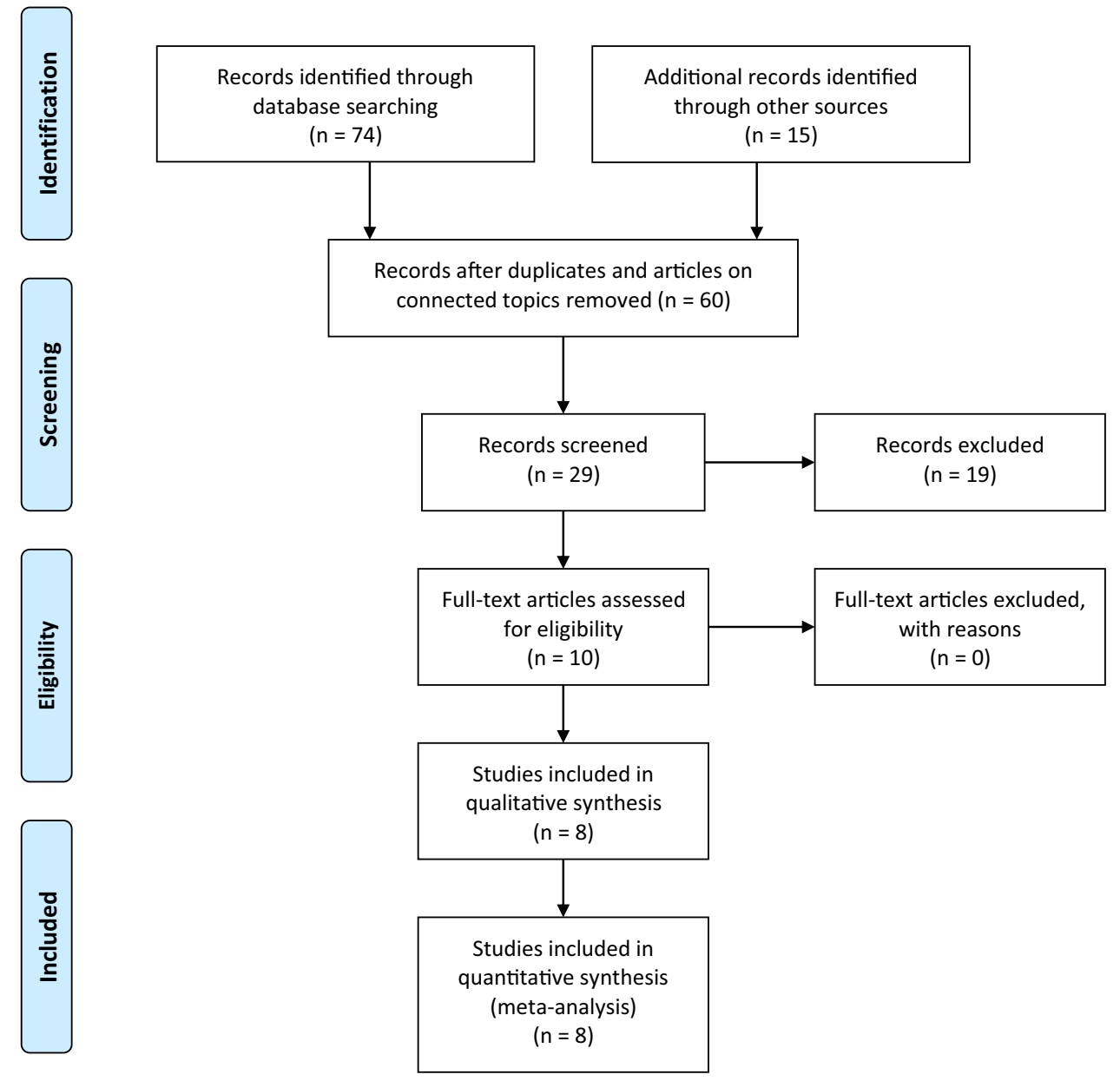

clearly stated. Moreover, such pseudoprogression appeared to be as high as $42 \%$ in one of the included studies. The rate of new trigeminal neuropathy was $9.9 \%$. The rate of facial nerve palsy appearance or worsening was $4.3 \%$. Of note, after first SRS, trigeminal preservation rates vary between 74 and $99 \%$ [8, 12, 21, 24, 31, 41, 44, 55] and facial preservation ranges between 84 and $100 \%$ [8, 12, 21, 24, 31,
41, 44, 55]. In a recent meta-analysis (which included 45 articles and 4234 patients), the crude rate of hearing preservation after first SRS was $51 \%$ at a median follow-up period of $44+/-32$ months [60]. In the present meta-analysis, the rate of hearing loss was $54.3 \%$ going up to as high as $83.8 \%$. The rate of hearing loss after second SRS appears similar to the one after first SRS.
Fig. 2 Number of patients in repeat SRS series as per overall series with first SRS

\section{Number of patients in repeat SRS as per overall series with first SRS}

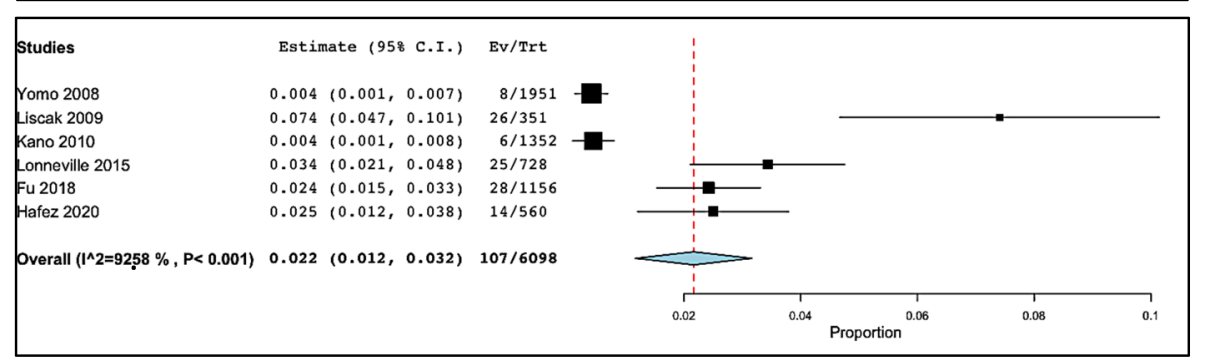


Fig. 3 Tumor control rates after SRS for VS: a stability; b tumor; $\mathbf{c}$ progression rates

\section{Tumor control after repeat SRS}

\section{a}

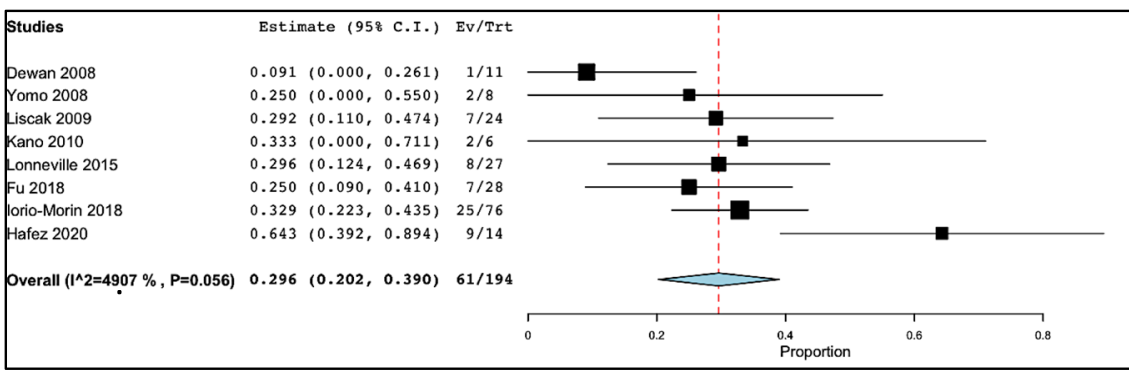

b

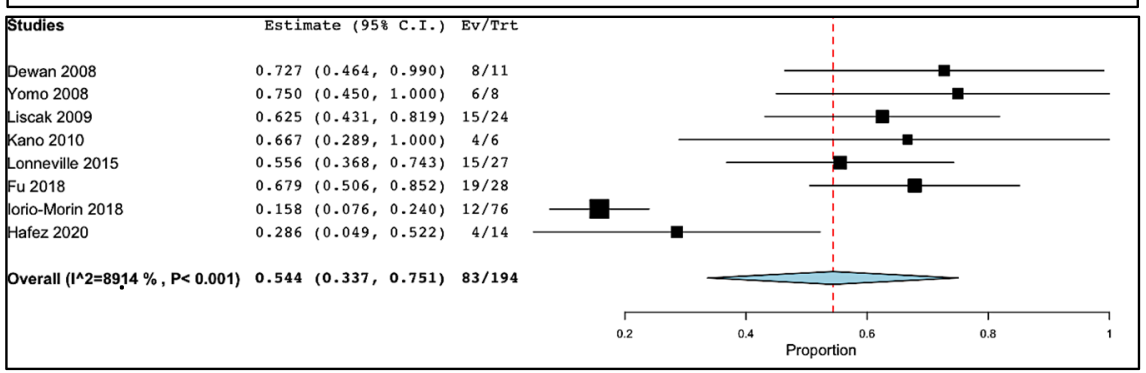

C

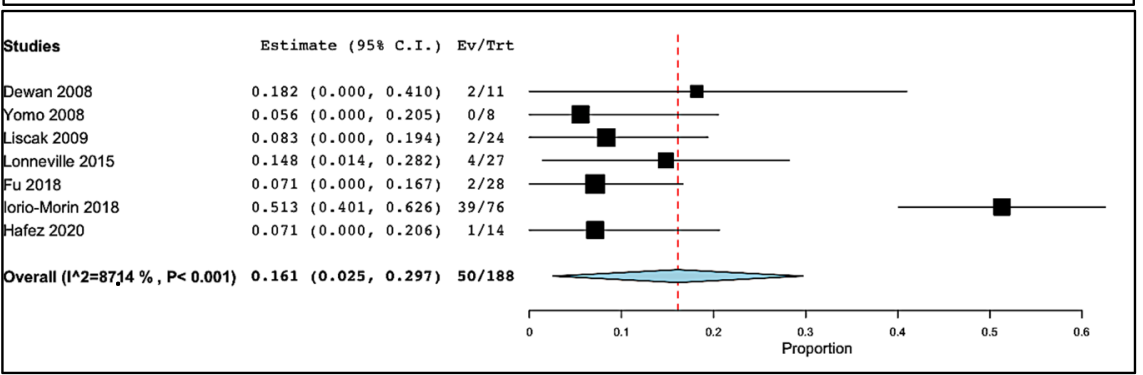

The largest series included in the present meta-analysis was the one of Iorio-Morin et al. [15] which analyzed 76 patients. The authors reported high actuarial tumor control rates at 2, 5, and 10 years following SRS of $98.6 \%, 92.2 \%$, and $92.2 \%$, respectively. Worsening of the facial nerve function attained 7\%. In another series, Fu et al. [9] reported $100 \%$ tumor control after second SRS after a median followup period of 75 months. Volumetric tumor response after the second procedure could not be predicted by the volumetric response after first SRS. Thus, the authors concluded that this justifies considering repeat SRS even for tumors that did not show any volumetric response and displayed continuous growth after first treatment. Moreover, there is an increased risk of mild facial and trigeminal nerve dysfunction after second as compared to first SRS. Such results fairly compared to what is reported here in our meta-analysis.

The timing for retreatment after first SRS failure for VS has been controversial in the current literature. Retreatment indication for microsurgery or SRS is usually related to tumor (volume, edema) or patient (age, symptoms, medical comorbidities) specific factors. With regard to tumor-related aspects, one should keep also in mind the probability of transient tumor expansion (TTE) [42], which varies between 17 and $74 \%$ of patients after first GK $[13,35,62]$. Classically, TTE typically occurs between 3 and 9 months after first GK treatment, with a peak at 6 months, induced by internal swelling [34]. This should not be confounded with real tumor progression. 
Fig. 4 Specific cranial nerve outcomes after SRS: a trigeminal; b facial; c cochlear

\section{Cranial nerve outcome after repeat SRS}

\section{a}

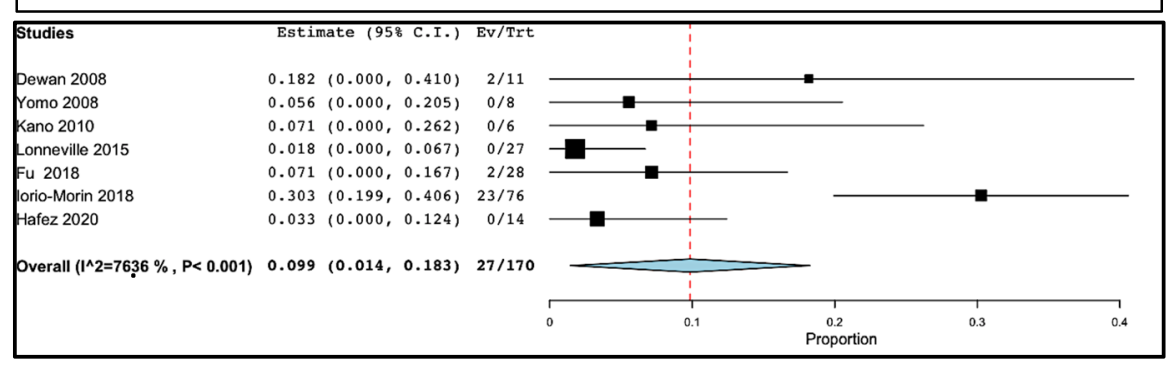

b

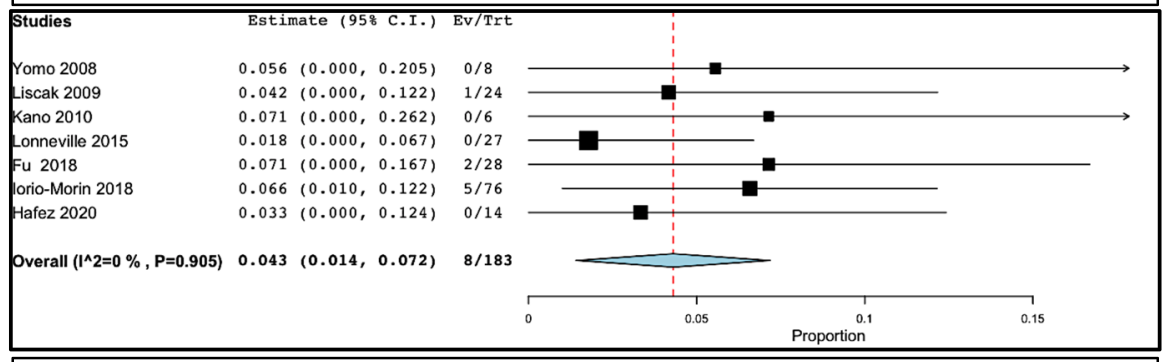

C

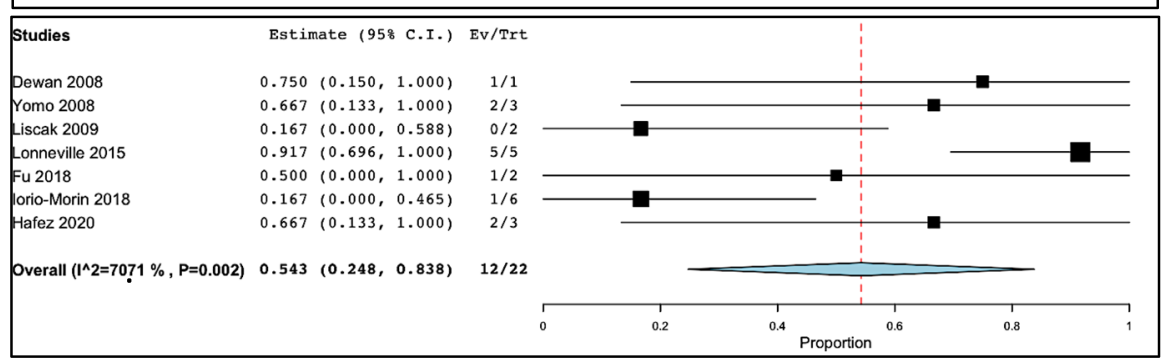

Subsequent volumetric measurement is the key to evaluate such progression, while some authors suggested even preradiosurgical radiomics [59]. One should keep in mind that at least 2 years follow-up is usually required [23], avoiding misjudging any temporary tumoral swelling [32]. This should be further judged in the context of presence or absence of patient's symptoms. Additional neuroimaging assessment (other than MRI) might be also useful. In a series by Lonneville et al. [27], the authors evaluated the role of PET during follow-up course, which showed a significant metabolic decrease of the tumor, further considered as TTE. Moreover, one other particular aspect is related to potential cystic components or entrapment cysts [29], the latter with much-complicated decision making, depending on the clinical context [53]. With regard to patient-related aspects, indications for additional management after initial GK might include trigeminal neuropathy (numbness, trigeminal pain, facial neuropathy), facial neuropathy (palsy, hemifacial spasm [18]), or vestibular (major imbalance).

In line with the previous, the definition of treatment failure after first SRS is not always straightforward. In our opinion, several key aspects should be considered before concluding treatment failure: duration of at least 2 years after first SRS (preferably even 3-4 years, unless symptomatic mass effect) and minimum 3 time points of follow-up MRI displaying continuous growth. Further decision to retreat should be delayed in absence of symptomatic mass effect. Transient tumor expansion should always be kept in mind, and is frequently associated with transient loss of central contrast enhancement. Clinically relevant tumor progression should be certainly differentiated from TTE and should rule 
the therapeutic decision. The neurosurgical team involved in decision making should be aware of classical changes after SRS.

Following primary SRS, 5-year tumor control rate is 90-98\% [1, 3, 28]. The key factor in retreating VSs with SRS is to formally consider that first SRS was a failure. In some series [11], the indication for retreatment was small- to medium-sized VS, less than $30 \mathrm{~mm}$ in diameter with documented tumor growth. While a vast majority of authors agree to irradiation of the whole VS during second SRS, some series advocated to irradiate only the progressive part of the tumor [27]. In our opinion, such an approach is not taking into account the radiobiological aspects [54], which might not consider several aspects pertinent to the tumor itself. Patients with a VS needing repeat treatment after initial SRS are a selected group of patients, with somehow unfavorable tumor response due to SRS and, most probably, a different radiobiological response. Another strategy, presented in the same study, was to perform even third irradiation for tumor growth [27]. However, such strategy might engender further TTE and additional symptoms. Advantages of SRS as preferred treatment modality in this indication are also related to avoid risks of open microsurgical resection, including meningitis (1-3\%) [45], hydrocephalus [40], or cerebro-spinal fluid leakage [2].

A key factor for tumor control is the marginal dose to be prescribed. Both in the literature and in our experience, we do not favor prescribing marginal doses of less than $11 \mathrm{~Gy}$ at the time of first or second GK. As illustrated here, some of the patients received even doses of less than $10 \mathrm{~Gy}$, which might explain failures of first and/or second SRS [20]

Here, we reported rates up to $10 \%$ of trigeminal nerve neuropathy. Such results should take into account the related volume of VS (close to the trigeminal nerve or in contact with the former). Also, dosimetric aspects are highly important, such as the location of the trigeminal root entry zone (REZ) in relationship with parts of the VS, REZ which should be visualized and excluded from the prescription isodose line, if possible. Another aspect is related to the interface with the brainstem, which should receive the steepest gradient during treatment planning [37]. Facial nerve neuropathy remains rare after repeat SRS, with an overall rate of $4.2 \%$, similar to that of first SRS. Hearing preservation is probably the most challenging aspect after second GK. The dose to the cochlea has been now standardly reported for first SRS $[30,50]$, but scarcely after the second one.

The effects of radiosurgery on the cochlear nerve in the literature have been frequently attributed to user technique. It has been previously acknowledged that the maximal dose received by the cochlea after a first SRS might play a role in hearing decline during follow-up course [50]. The data of cumulative cochlear dose (at first and second SRS, respectively) remain scarce and are frequently not reported. An additional aspect is that most users measure such dose only at the level of the modulus itself. Linskey et al. [25] suggested that the basal turn of the cochlea should also receive the lowest possible dose (ideally less than 4-5.3 Gy). Moreover, other authors advocated for a role of radiation dose rate, especially in the appearance of clinical acute and subacute effects after first SRS [52].

No patient developed radiation-induced tumors [58].

Future directions of clinical research shall include frequency of pseudoprogression phenomenon with the exact timing, MRI aspect, more clear definition of failure (clinical and/or radiological), and strong reliable markers of failure, including on neuroimaging.

Our meta-analysis has several inherent limitations. One limitation is related to patients, which previously received also another type of radiation. In this sense, only one patient included in a study [7] was previously treated with proton beam therapy (inside a series of 11 patients). However, in that series, the specific outcomes were not detailed as per patient. A second limitation is related to the minimal tumor coverage at the time of first SRS which varies depending on studies, as some authors reported a minimal cutoff of $90 \%$ [9]. This could have further influenced tumor control. A third limitation might be related to previously used treatment paradigms. Some series included, beside repeat GK after initial GK, a second GK after initial combined approach (subtotal microsurgical resection followed by SRS) [9]. Such tumors benefiting from previous microsurgical resection might have had a different radiobiology, although such aspect remains purely theoretical.

\section{Conclusion}

Repeat SRS after previously failed SRS for VS is associated with high tumor control rates. Tumor progression was reported in an overall rate of $16 \%$, while only some series reported further necessity of surgical management. Thus, in case of such progression, one should exclude a TTE. Cranial nerve outcomes remain favorable, particularly concerning the facial nerve. Hearing loss rates are similar to first SRS.

Author contribution Study supervision: Tuleasca. Drafting first version of the article: Balossier, Tuleasca. Revised first draft: all authors. Revised final version. all authors. Statistical analysis: Balossier, Tuleasca.

Funding Open Access funding provided by Université de Lausanne. Anne Balossier received a grant from the French Society of Neurosurgery for conducting her $\mathrm{PhD}$. Constantin Tuleasca gratefully acknowledges receipt of a "Young Researcher in Clinical Research Grant" (Jeune Chercheur en Recherche Clinique) from the University of Lausanne (UNIL), Faculty of Biology and Medicine (FBM), and the Lausanne University Hospital (CHUV). 
Data Availability Data is presented in tables and figures, as it is a systematic review.

\section{Code availability N/A}

\section{Declarations}

\section{Ethics approval N/A}

\section{Consent to participate N/A}

\section{Consent for publication N/A}

Conflict of interest The authors declare no competing interests.

Open Access This article is licensed under a Creative Commons Attribution 4.0 International License, which permits use, sharing, adaptation, distribution and reproduction in any medium or format, as long as you give appropriate credit to the original author(s) and the source, provide a link to the Creative Commons licence, and indicate if changes were made. The images or other third party material in this article are included in the article's Creative Commons licence, unless indicated otherwise in a credit line to the material. If material is not included in the article's Creative Commons licence and your intended use is not permitted by statutory regulation or exceeds the permitted use, you will need to obtain permission directly from the copyright holder. To view a copy of this licence, visit http://creativecommons.org/licenses/by/4.0/.

\section{References}

1. Boari N, Bailo M, Gagliardi F, Franzin A, Gemma M, del Vecchio A, Bolognesi A, Picozzi P, Mortini P (2014) Gamma Knife radiosurgery for vestibular schwannoma: clinical results at long-term follow-up in a series of 379 patients. J Neurosurg 121(Suppl):123142. https://doi.org/10.3171/2014.8.GKS141506

2. Briggs RJ, Fabinyi G, Kaye AH (2000) Current management of acoustic neuromas: review of surgical approaches and outcomes. J Clin Neurosci 7:521-526. https://doi.org/10.1054/jocn.2000.0728

3. Chung WY, Liu KD, Shiau CY, Wu HM, Wang LW, Guo WY, Ho DM, Pan DH (2005) Gamma Knife surgery for vestibular schwannoma: 10-year experience of 195 cases. J Neurosurg 102(Suppl):87-96

4. Coelho DH, Tang Y, Suddarth B, Mamdani M (2018) MRI surveillance of vestibular schwannomas without contrast enhancement: clinical and economic evaluation. Laryngoscope 128:202209. https://doi.org/10.1002/lary.26589

5. Copeland WR, Hoover JM, Morris JM, Driscoll CL, Link MJ (2013) Use of preoperative MRI to predict vestibular schwannoma intraoperative consistency and facial nerve outcome. Journal of neurological surgery Part B, Skull base 74:347-350. https://doi.org/10.1055/s-0033-1347369

6. Daniel RT, Tuleasca C, George M, Pralong E, Schiappacasse L, Zeverino M, Maire R, Levivier M (2017) Preserving normal facial nerve function and improving hearing outcome in large vestibular schwannomas with a combined approach: planned subtotal resection followed by Gamma Knife radiosurgery. Acta Neurochir 159:1197-1211. https://doi.org/10.1007/ s00701-017-3194-0

7. Dewan S, Noren G (2008) Retreatment of vestibular schwannomas with Gamma Knife surgery. J Neurosurg 109(Suppl):144-148. https://doi.org/10.3171/JNS/2008/109/12/S22
8. Friedman WA, Bradshaw P, Myers A, Bova FJ (2006) Linear accelerator radiosurgery for vestibular schwannomas. J Neurosurg 105:657-661. https://doi.org/10.3171/jns.2006.105.5.657

9. Fu VX, Verheul JB, Beute GN, Leenstra S, Kunst HPM, Mulder JJS, Hanssens PEJ (2018) Retreatment of vestibular schwannoma with Gamma Knife radiosurgery: clinical outcome, tumor control, and review of literature. J Neurosurg 129:137-145. https://doi.org/ 10.3171/2017.3.JNS162033

10. Gardner G, Robertson JH (1988) Hearing preservation in unilateral acoustic neuroma surgery. Ann Otol Rhinol Laryngol 97:55-66. https://doi.org/10.1177/000348948809700110

11. Hafez RFA, Morgan MS, Fahmy OM, Hassan HT (2020) Outcomes of Gamma Knife surgery retreatment for growing vestibular schwannoma and review of the literature. Clin Neurol Neurosurg 198:106171. https://doi.org/10.1016/j.clineuro.2020.106171

12. Hasegawa T, Kida Y, Kato T, lizuka H, Kuramitsu S, Yamamoto T (2013) Long-term safety and efficacy of stereotactic radiosurgery for vestibular schwannomas: evaluation of 440 patients more than 10 years after treatment with Gamma Knife surgery. J Neurosurg 118:557-565. https://doi.org/10.3171/2012.10.JNS12523

13. Hasegawa T, Kida Y, Yoshimoto M, Koike J, Goto K (2006) Evaluation of tumor expansion after stereotactic radiosurgery in patients harboring vestibular schwannomas. Neurosurgery 58:1119-1128; discussion 1119-1128. https://doi.org/10.1227/ 01.NEU.0000215947.35646.DD

14 House JW, Brackmann DE (1985) Facial nerve grading system. Otolaryngol Head Neck Surg 93:146-147. https://doi.org/10.1177/ 019459988509300202

15. Iorio-Morin C, Liscak R, Vladyka V, Kano H, Jacobs RC, Lunsford LD, Cohen-Inbar O, Sheehan J, Emad R, Karim KA, El-Shehaby A, Reda WA, Lee CC, Pai FY, Wolf A, Kondziolka D, Grills I, Lee KC, Mathieu D (2019) Repeat stereotactic radiosurgery for progressive or recurrent vestibular schwannomas. Neurosurgery 85:535-542. https://doi.org/10.1093/neuros/nyy416

16. Iwai Y, Ishibashi K, Watanabe Y, Uemura G, Yamanaka K (2015) Functional preservation after planned partial resection followed by Gamma Knife radiosurgery for large vestibular schwannomas. World neurosurgery 84:292-300. https://doi.org/10.1016/j.wneu. 2015.03.012

17. Johnson S, Kano H, Faramand A, Pease M, Nakamura A, Hassib M, Spencer D, Sisterson N, Faraji AH, Arai Y, Monaco E, Niranjan A, Flickinger JC, Lunsford LD (2019) Long term results of primary radiosurgery for vestibular schwannomas. J Neurooncol 145:247-255. https://doi.org/10.1007/s11060-019-03290-0

18. Kano H, Kondziolka D, Niranjan A, Flannery TJ, Flickinger JC, Lunsford LD (2010) Repeat stereotactic radiosurgery for acoustic neuromas. Int J Radiat Oncol Biol Phys 76:520-527. https://doi. org/10.1016/j.ijrobp.2009.01.076

19. Kentala E, Pyykko I (2001) Clinical picture of vestibular schwannoma. Auris Nasus Larynx 28:15-22. https://doi.org/10.1016/ s0385-8146(00)00093-6

20. Kondziolka D, Lunsford LD, McLaughlin MR, Flickinger JC (1998) Long-term outcomes after radiosurgery for acoustic neuromas. N Engl J Med 339:1426-1433. https://doi.org/10.1056/ NEJM199811123392003

21. Kondziolka D, Mousavi SH, Kano H, Flickinger JC, Lunsford LD (2012) The newly diagnosed vestibular schwannoma: radiosurgery, resection, or observation? Neurosurg Focus 33:E8. https:// doi.org/10.3171/2012.6.FOCUS12192

22. Lees KA, Tombers NM, Link MJ, Driscoll CL, Neff BA, Van Gompel JJ, Lane JI, Lohse CM, Carlson ML (2018) Natural history of sporadic vestibular schwannoma: a volumetric study of tumor growth. Otolaryngol Head Neck Surg 159:535-542. https:// doi.org/10.1177/0194599818770413

23. Li L-F, Yu C-P, Tsang AC-O, Taw BB-T, Lui W-M (2020) Nearcomplete regression 19 years after Gamma Knife radiosurgery 
of vestibular schwannoma with massive pseudoprogression: case report. J Neurosurg 1-4. https://doi.org/10.3171/2020.3.JNS20 3892020.3.JNS20389

24. Lin D, Hegarty JL, Fischbein NJ, Jackler RK (2005) The prevalence of "incidental" acoustic neuroma. Arch Otolaryngol Head Neck Surg 131:241-244. https://doi.org/10.1001/archotol.131.3. 241

25. Linskey ME (2008) Hearing preservation in vestibular schwannoma stereotactic radiosurgery: what really matters? J Neurosurg 109(Suppl):129-136. https://doi.org/10.3171/JNS/2008/109/12/ S20

26. Liscak R, Vladyka V, Urgosik D, Simonova G, Vymazal J (2009) Repeated treatment of vestibular schwannomas after gamma knife radiosurgery. Acta Neurochir (Wien) 151:317-324; discussion 324. https://doi.org/10.1007/s00701-009-0254-0

27. Lonneville S, Delbrouck C, Renier C, Devriendt D, Massager N (2015) Repeat Gamma Knife surgery for vestibular schwannomas. Surg Neurol Int 6:153. https://doi.org/10.4103/2152-7806.166173

28. Lunsford LD, Niranjan A, Flickinger JC, Maitz A, Kondziolka D (2005) Radiosurgery of vestibular schwannomas: summary of experience in 829 cases. J Neurosurg 102(Suppl):195-199

29. Massaad E, Hamidi N, Goetz J, Padmanaban V, Mau C, Tsang D, de Moraes FY, Chung C, Zacharia BE, Mansouri A (2021) Equivalent efficacy and safety of radiosurgery for cystic and solid vestibular schwannomas: a systematic review. World neurosurgery 146(322-331):e321. https://doi.org/10.1016/j.wneu.2020.11.040

30. Massager N, Nissim O, Delbrouck C, Delpierre I, Devriendt D, Desmedt F, Wikler D, Brotchi J, Levivier M (2007) Irradiation of cochlear structures during vestibular schwannoma radiosurgery and associated hearing outcome. J Neurosurg 107:733-739. https://doi.org/10.3171/JNS-07/10/0733

31. Meijer OW, Weijmans EJ, Knol DL, Slotman BJ, Barkhof F, Vandertop WP, Castelijns JA (2008) Tumor-volume changes after radiosurgery for vestibular schwannoma: implications for followup MR imaging protocol. AJNR Am J Neuroradiol 29:906-910. https://doi.org/10.3174/ajnr.A0969

32. Mindermann T, Schlegel I (2014) How to distinguish tumor growth from transient expansion of vestibular schwannomas following Gamma Knife radiosurgery. Acta Neurochir 156:11211123. https://doi.org/10.1007/s00701-014-2063-3

33. Moher D, Liberati A, Tetzlaff J, Altman DG, Group P (2009) Reprint-preferred reporting items for systematic reviews and meta-analyses: the PRISMA statement. Phys Ther 89:873-880

34. Nagano O, Higuchi Y, Serizawa T, Ono J, Matsuda S, Yamakami I, Saeki N (2008) Transient expansion of vestibular schwannoma following stereotactic radiosurgery. J Neurosurg 109:811-816. https://doi.org/10.3171/JNS/2008/109/11/0811

35. Nakamura H, Jokura H, Takahashi K, Boku N, Akabane A, Yoshimoto T (2000) Serial follow-up MR imaging after gamma knife radiosurgery for vestibular schwannoma. AJNR Am J Neuroradiol 21:1540-1546

36. Ozgen B, Oguz B, Dolgun A (2009) Diagnostic accuracy of the constructive interference in steady state sequence alone for followup imaging of vestibular schwannomas. AJNR Am J Neuroradiol 30:985-991. https://doi.org/10.3174/ajnr.A1472

37. Peciu-Florianu I, Regis J, Levivier M, Dedeciusova M, Reyns N, Tuleasca C (2020) Trigeminal neuralgia secondary to meningiomas and vestibular schwannoma is improved after stereotactic radiosurgery: a systematic review and meta-analysis. StereotactFunctNeurosurg 99:1-11. https://doi.org/10.1159/000509842

38. Perry A, Graffeo CS, Copeland WR 3rd, Carlson ML, Neff BA, Driscoll CL, Link MJ (2017) Microsurgery for recurrent vestibular schwannoma after previous gross total resection. Otol Neurotol 38:882-888. https://doi.org/10.1097/MAO.0000000000001402
39. Pinna MH, Bento RF, Neto RV (2012) Vestibular schwannoma: 825 cases from a 25-year experience. Int Arch Otorhinolaryngol 16:466-475. https://doi.org/10.7162/S1809-97772012000400007

40. Pollock BE, Driscoll CL, Foote RL, Link MJ, Gorman DA, Bauch CD, Mandrekar JN, Krecke KN, Johnson CH (2006) Patient outcomes after vestibular schwannoma management: a prospective comparison of microsurgical resection and stereotactic radiosurgery. Neurosurgery 59:77-85; discussion 77-85. https://doi.org/ 10.1227/01.NEU.0000219217.14930.14

41. Regis J, Carron R, Park MC, Soumare O, Delsanti C, Thomassin JM, Roche PH (2010) Wait-and-see strategy compared with proactive Gamma Knife surgery in patients with intracanalicular vestibular schwannomas. J Neurosurg 113(Suppl):105-111. https:// doi.org/10.3171/2010.8.GKS101058

42. Regis J, Delsanti C, Roche PH (2017) Editorial: Vestibular schwannoma radiosurgery: progression or pseudoprogression? J Neurosurg 127:374-379. https://doi.org/10.3171/2016.7.JNS16 1236

43. Regis J, Pellet W, Delsanti C, Dufour H, Roche PH, Thomassin JM, Zanaret M, Peragut JC (2002) Functional outcome after Gamma Knife surgery or microsurgery for vestibular schwannomas. J Neurosurg 97:1091-1100. https://doi.org/10.3171/jns.2002. 97.5.1091

44. Regis J, Tamura M, Delsanti C, Roche PH, Pellet W, Thomassin JM (2008) Hearing preservation in patients with unilateral vestibular schwannoma after Gamma Knife surgery. Prog Neurol Surg 21:142-151. https://doi.org/10.1159/000156901156901[pii]

45. Samii M, Matthies C (1997) Management of 1000 vestibular schwannomas (acoustic neuromas): the facial nerve--preservation and restitution of function. Neurosurgery 40:684-694; discussion 694-685.https://doi.org/10.1097/00006123-199704000-00006

46. Schmidt RF, Boghani Z, Choudhry OJ, Eloy JA, Jyung RW, Liu JK (2012) Incidental vestibular schwannomas: a review of prevalence, growth rate, and management challenges. Neurosurg Focus 33:E4. https://doi.org/10.3171/2012.7.FOCUS12186

47. Stangerup SE, Tos M, Thomsen J, Caye-Thomasen P (2010) True incidence of vestibular schwannoma? Neurosurgery 67:13351340; discussion 1340. https://doi.org/10.1227/NEU.0b013e3181 f22660

48. Starnoni D, Daniel RT, Tuleasca C, George M, Levivier M, Messerer M (2018) Systematic review and meta-analysis of the technique of subtotal resection and stereotactic radiosurgery for large vestibular schwannomas: a "nerve-centered" approach. Neurosurg Focus 44:E4. https://doi.org/10.3171/2017.12.FOCUS 17669

49. Starnoni D, Giammattei L, Cossu G, Link MJ, Roche PH, Chacko AG, Ohata K, Samii M, Suri A, Bruneau M, Cornelius JF, Cavallo L, Meling TR, Froelich S, Tatagiba M, Sufianov A, Paraskevopoulos D, Zazpe I, Berhouma M, Jouanneau E, Verheul JB, Tuleasca C, George M, Levivier M, Messerer M, Daniel RT (2020) Surgical management for large vestibular schwannomas: a systematic review, meta-analysis, and consensus statement on behalf of the EANS skull base section. Acta Neurochir (Wien) 162:2595-2617. https://doi.org/10.1007/s00701-020-04491-7

50. Tamura M, Carron R, Yomo S, Arkha Y, Muraciolle X, Porcheron D, Thomassin JM, Roche PH, Regis J (2009) Hearing preservation after gamma knife radiosurgery for vestibular schwannomas presenting with high-level hearing. Neurosurgery 64:289-296; discussion 296.https://doi.org/10.1227/01.NEU.0000338256. 87936.7C

51. Tsao MN, Sahgal A, Xu W, De Salles A, Hayashi M, Levivier M, Ma L, Martinez R, Regis J, Ryu S, Slotman BJ, Paddick I (2017) Stereotactic radiosurgery for vestibular schwannoma: International Stereotactic Radiosurgery Society (ISRS) practice guideline. Journal of radiosurgery and SBRT 5:5-24 
52. Tuleasca C, George M, Faouzi M, Schiappacasse L, Leroy HA, Zeverino M, Daniel RT, Maire R, Levivier M (2016) Acute clinical adverse radiation effects after Gamma Knife surgery for vestibular schwannomas. J Neurosurg 125:73-82. https://doi.org/10. 3171/2016.7.GKS161496

53. Tuleasca C, George M, Maire R, Schiappacasse L, Marguet M, Daniel RT, Levivier M (2017) Letter: Cystic vestibular schwannomas respond best to radiosurgery. Neurosurgery 81:E80-E82. https://doi.org/10.1093/neuros/nyx462

54. Tuleasca C, Peciu-Florianu I, Leroy H-A, Vermandel M, Faouzi M, Reyns N (2020) Biologically effective dose and prediction of obliteration of unruptured arteriovenous malformations treated by upfront Gamma Knife radiosurgery: a series of 149 consecutive cases. J Neurosurg 1-11. https://doi.org/10.3171/2020.4.JNS20 12502020.4.JNS201250

55. van de Langenberg R, Hanssens PE, van Overbeeke JJ, Verheul JB, Nelemans PJ, de Bondt BJ, Stokroos RJ (2011) Management of large vestibular schwannoma. Part I. Planned subtotal resection followed by Gamma Knife surgery: radiological and clinical aspects. J Neurosurg 115:875-884. https://doi.org/10.3171/ 2011.6.JNS101958

56. Varughese JK, Breivik CN, Wentzel-Larsen T, Lund-Johansen M (2012) Growth of untreated vestibular schwannoma: a prospective study. J Neurosurg 116:706-712. https://doi.org/10.3171/2011.12. JNS111662

57. Vernooij MW, Ikram MA, Tanghe HL, Vincent AJ, Hofman A, Krestin GP, Niessen WJ, Breteler MM, van der Lugt A (2007) Incidental findings on brain MRI in the general population. N Engl J Med 357:1821-1828. https://doi.org/10.1056/NEJMoa070972
58. Wolf A, Naylor K, Tam M, Habibi A, Novotny J, Liscak R, Martinez-Moreno N, Martinez-Alvarez R, Sisterson N, Golfinos JG, Silverman J, Kano H, Sheehan J, Lunsford LD, Kondziolka D (2019) Risk of radiation-associated intracranial malignancy after stereotactic radiosurgery: a retrospective, multicentre, cohort study. Lancet Oncol 20:159-164. https://doi.org/10.1016/S14702045(18)30659-4

59. Yang HC, Wu CC, Lee CC, Huang HE, Lee WK, Chung WY, Wu HM, Guo WY, Wu YT, Lu CF (2020) Prediction of pseudoprogression and long-term outcome of vestibular schwannoma after Gamma Knife radiosurgery based on preradiosurgical MR radiomics. Radiother Oncol 155:123-130. https://doi.org/10.1016/j. radonc.2020.10.041

60. Yang I, Sughrue ME, Han SJ, Aranda D, Pitts LH, Cheung SW, Parsa AT (2010) A comprehensive analysis of hearing preservation after radiosurgery for vestibular schwannoma. J Neurosurg 112:851-859. https://doi.org/10.3171/2009.8.JNS0985

61. Yomo S, Arkha Y, Delsanti C, Roche PH, Thomassin JM, Regis J (2009) Repeat Gamma Knife surgery for regrowth of vestibular schwannomas. Neurosurgery 64:48-54; discussion 54-45. https:// doi.org/10.1227/01.NEU.0000327692.74477.D5

62. Yu CP, Cheung JY, Leung S, Ho R (2000) Sequential volume mapping for confirmation of negative growth in vestibular schwannomas treated by Gamma Knife radiosurgery. J Neurosurg 93(Suppl 3):82-89. https://doi.org/10.3171/jns.2000.93.supplement

Publisher's Note Springer Nature remains neutral with regard to jurisdictional claims in published maps and institutional affiliations.

\section{Authors and Affiliations}

\section{Anne Balossier ${ }^{1,2} \cdot$ Jean Régis ${ }^{1,2} \cdot$ Nicolas Reyns $^{3,4} \cdot$ Pierre-Hugues Roche $^{5} \cdot$ Roy Thomas Daniel $^{6,7} \cdot$ Mercy George $^{8}$. Mohamed Faouzi $^{9} \cdot$ Marc Levivier $^{6,7} \cdot$ Constantin Tuleasca ${ }^{6,7,10}$}

1 Functional, and Stereotactic Neurosurgery Service and Gamma Knife Unit, Assistance Publique - Hôpitaux de Marseille, Timone Hospital, Marseille, France

2 Aix-Marseille University, Inserm, INS, Inst Neurosci Syst, Marseille, France

3 University of Lille, Inserm, CHU de Lille, U1189 - ONCO-THAI -Laser Assisted Therapies and Immunotherapies for Oncology, F-59000 Lille, France

4 Neurosurgery and Neurooncology Department, CHU de Lille, F-59000 Lille, France

5 Neurosurgery Service, Neurochirurgie Hôpital Nord, Pôle NEUROSCIENCES, Hôpital Nord, Marseille, France
6 Department of Clinical Neurosciences, Neurosurgery Service and Gamma Knife Center, Centre Hospitalier Universitaire Vaudois (CHUV), Lausanne, Switzerland

7 Faculty of Biology and Medicine (FBM), University of Lausanne (Unil), Lausanne, Switzerland

8 Department of Otorhinolaryngology, Head \& Neck Surgery, Centre Hospitalier Universitaire Vaudois (CHUV), Lausanne, Switzerland

9 Division of Biostatistics, Center for Primary Care and Public Health (Unisanté), Université de Lausanne, Lausanne, Switzerland

10 Signal Processing Laboratory (LTS 5), École Polytechnique Fédérale de Lausanne (EPFL), Lausanne, Switzerland 